\title{
Correction for: Environmental radionuclide concentrations below which non-human biota experience no effects
}

\section{Radioprotection 44(5), 107-114 (2009) https://doi.org/10.1051/radiopro/20095025}

\author{
S.L. Chouhan*, T.L. Yankovich and P.A. Davis \\ Canadian Nuclear Laboratories, Chalk River, Ontario, Canada.
}

Received: 8 October 2019 / Accepted: 16 October 2019

The authors indicated that the units in the first row of Table 4 in the original publication were not placed in the correct column. Table 4 thus must be read as follow. This correction does not change the assertions or the conclusions of the authors.

Table 4. Generic radionuclide concentrations below which no radiological effects are expected on non-human biota at Canadian CANDU sites.

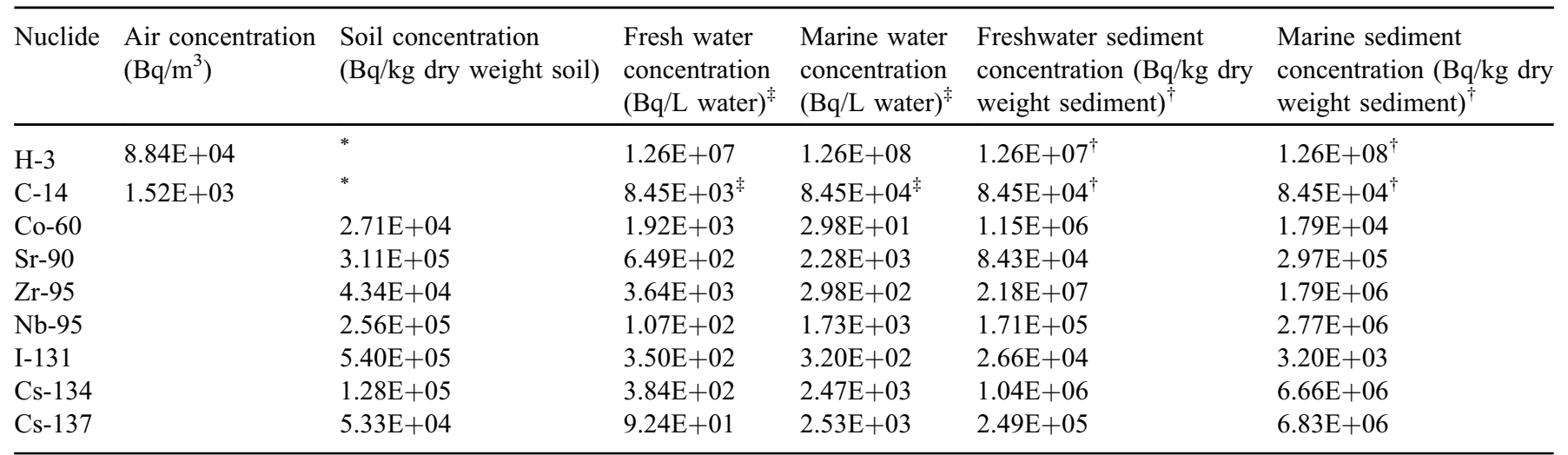

\footnotetext{
*: In most cases, the air concentrations of HTO and C-14 are available and can be used to ensure the protection of biota. In rare cases where soil concentrations are required, they can be calculated using the specific activity model.

¥: Unit is $\mathrm{Bq} / \mathrm{g}$ dissolved inorganic carbon in water for $\mathrm{C}-14$.

${ }^{\dagger}$ : Units are $\mathrm{Bq} / \mathrm{L}$ of sediment water for $\mathrm{HTO}$; and $\mathrm{Bq} / \mathrm{g}$ total organic carbon in sediment for $\mathrm{C}-14$.
} 